\title{
Sinergismo na combinação de glifosato e saflufenacil para o controle de buva ${ }^{1}$
}

\author{
Giliardi Dalazen², Nelson Diehl Kruse ${ }^{3}$, Sérgio Luiz de Oliveira Machado ${ }^{3}$, Andrisa Balbinot ${ }^{3}$
}

\begin{abstract}
Synergism of the glyphosate and saflufenacil combination for controlling hairy fleabane

In Brazil, hairy fleabane stands out among the main weeds of soybean crops, due to its aggressiveness and resistance to glyphosate. Thus, to avoid the selection of resistant populations to the glyphosate herbicide, the use of other herbicides has become critical to the management of this weed. This study aimed to evaluate the control efficiency of glyphosate and saflufenacil herbicides in hairy fleabane plants (Conyza bonariensis), as well as the type of interaction of the combination of those herbicides for controlling glyphosate-resistant hairy fleabane. A randomized blocks design, with four replications, was used. Treatments consisted of glyphosate doses $\left(0 \mathrm{~g} \mathrm{ha}^{-1} ; 270 \mathrm{~g} \mathrm{ha}^{-1} ; 540 \mathrm{~g} \mathrm{ha}^{-1} ; 1,080 \mathrm{~g} \mathrm{ha}^{-1} ; 2,160 \mathrm{~g} \mathrm{ha}^{-1}\right.$; $4,320 \mathrm{~g} \mathrm{ha}^{-1} ; 8,640 \mathrm{~g} \mathrm{ha}^{-1} ; 17,280 \mathrm{~g} \mathrm{ha}^{-1}$ ) combined with saflufenacil (0 $\mathrm{g} \mathrm{ha}^{-1} ; 0.55 \mathrm{~g} \mathrm{ha}^{-1} ; 1.09 \mathrm{~g} \mathrm{ha}^{-1} ; 2.18 \mathrm{~g} \mathrm{ha}^{-1} ; 4.37 \mathrm{~g} \mathrm{ha}^{-1}$; $8.75 \mathrm{~g} \mathrm{ha}^{-1} ; 17.5 \mathrm{~g} \mathrm{ha}^{-1} ; 35 \mathrm{~g} \mathrm{ha}^{-1}$ ), making six dose-response curves. A synergistic effect was observed between the glyphosate and saflufenacil herbicides for controlling the glyphosate-resistant hairy fleabane, being the mixture considered efficient for the biotype studied. Furthermore, the addition of glyphosate $\left(540 \mathrm{~g} \mathrm{ha}^{-1}\right)$ to the saflufenacil herbicide $\left(35 \mathrm{~g} \mathrm{ha}^{-1}\right)$ prevented the occurrence of regrowth and the dispersion of new hairy fleabane seeds, what does not occur in plants treated exclusively with saflufenacil.
\end{abstract}

KEY-WORDS: Conyza bonariensis; synergistic effect; herbicide.

\section{INTRODUÇÃO}

Com o uso intensivo de glifosato, populações de buva resistentes a esse herbicida foram identificadas em lavouras de soja do Brasil, a partir do ano de 2005 (Lamego \& Vidal 2008). Atualmente, a buva destaca-se como a planta daninha resistente ao glifosato com maior distribuição mundial (Heap 2014). Devido à rápida seleção e dispersão da resistência,

\section{RESUMO}

No Brasil, a buva destaca-se entre as principais plantas daninhas da cultura da soja, devido à sua agressividade e resistência ao glifosato. Dessa forma, para evitar a seleção de populações resistentes ao herbicida glifosato, o uso de outros herbicidas tornou-se fundamental para o manejo dessa planta daninha. Este estudo objetivou avaliar a eficiência de controle dos herbicidas glifosato e saflufenacil em plantas de buva (Conyza bonariensis), bem como o tipo de interação da combinação desses herbicidas no controle de buva resistente a glifosato. O delineamento utilizado foi o de blocos ao acaso, com quatro repetições. Os tratamentos foram compostos por combinações de doses de glifosato $\left(0 \mathrm{~g} \mathrm{ha}^{-1} ; 270 \mathrm{~g} \mathrm{ha}^{-1}\right.$; $540 \mathrm{~g} \mathrm{ha}^{-1} ; 1.080 \mathrm{~g} \mathrm{ha}^{-1} ; 2.160 \mathrm{~g} \mathrm{ha}^{-1} ; 4.320 \mathrm{~g} \mathrm{ha}^{-1} ; 8.640 \mathrm{~g} \mathrm{ha}^{-1}$; $\left.17.280 \mathrm{~g} \mathrm{ha}^{-1}\right)$ e saflufenacil $\left(0 \mathrm{~g} \mathrm{ha}^{-1} ; 0,55 \mathrm{~g} \mathrm{ha}^{-1} ; 1,09 \mathrm{~g} \mathrm{ha}^{-1}\right.$; 2,18 $\left.\mathrm{g} \mathrm{ha}^{-1} ; 4,37 \mathrm{~g} \mathrm{ha}^{-1} ; 8,75 \mathrm{~g} \mathrm{ha}^{-1} ; 17,5 \mathrm{~g} \mathrm{ha}^{-1} ; 35 \mathrm{~g} \mathrm{ha}^{-1}\right)$, formando seis curvas de dose-resposta. Houve efeito sinérgico entre os herbicidas glifosato e saflufenacil para o controle de buva resistente ao glifosato, sendo a mistura considerada eficiente para o biótipo estudado. Além disso, a adição de glifosato (540 $\mathrm{g} \mathrm{ha}^{-1}$ ) ao herbicida saflufenacil (35 $\left.\mathrm{g} \mathrm{ha}^{-1}\right)$ preveniu a ocorrência de rebrote e a dispersão de novas sementes de buva, o que não ocorre em plantas tratadas apenas com saflufenacil.

PALAVRAS-CHAVE: Conyza bonariensis; efeito sinérgico; herbicida.

o controle dessa planta tornou-se ineficiente quando utilizado apenas o herbicida glifosato, demandando a adoção de novas estratégias de controle, tal como a combinação com outro herbicida (Culpepper 2006, Wilson et al. 2007).

O glifosato é um herbicida não seletivo, que inibe a atividade da enzima 5- enolpiruvil-chiquimato-3-fosfato sintase (EPSPS), responsável pela síntese dos aminoácidos triptofano, fenilalanina e tirosina

1. Trabalho recebido em jan./2015 e aceito para publicação em jun./2015 (http://dx.doi.org/10.1590/1983-40632015v4533708).

2. Universidade Federal do Rio Grande do Sul (UFRGS), Faculdade de Agronomia, Departamento de Plantas de Lavoura,

Porto Alegre, RS, Brasil. E-mail: giliardidalazen@gmail.com.

3. Universidade Federal de Santa Maria (UFSM), Departamento de Defesa Fitossanitária, Santa Maria, RS, Brasil.

E-mails: nelsondkruse@gmail.com,slomachado@yahoo.com.br, andribalbinot@hotmail.com. 
(Zablotowicz \& Reddy 2007). Depois de aplicado, move-se prontamente através do floema, seguindo a rota dos produtos da fotossíntese (Rodrigues \& Almeida 2011).

Como herbicida alternativo para ser misturado ao glifosato no controle de buva resistente a este herbicida encontra-se o saflufenacil, que é um novo herbicida inibidor da enzima protoporfirinogênio IX oxidase (PPO) (Grossmann et al. 2010), que catalisa a conversão do protoporfirinogênio IX para protoporfirina IX. O bloqueio dessa rota metabólica previne a síntese de clorofila e citocromos no cloroplasto, além de gerar espécies reativas de oxigênio no citosol, com posterior estresse oxidativo nas membranas e extravasamento do conteúdo celular (Beale \& Weistein 1990).

O saflufenacil foi comercialmente introduzido no Brasil em 2013 e em outros países em 2010, sendo recomendado para a dessecação de culturas, controle em pré-semeadura e como herbicida pré-emergente, para a maioria das plantas daninhas eudicotiledôneas (Grossmann et al. 2011).

Historicamente, a combinação de glifosato com herbicidas inibidores da enzima PPO, tais como o fomesafen e sulfentrazone, resulta em antagonismo, devido à rápida destruição dos tecidos causada por herbicidas de contato, reduzindo a eficiência de ambos os herbicidas (Starke \& Oliver 1998, Shaw \& Arnold 2002). No entanto, ao contrário dos demais herbicidas inibidores da enzima PPO, o saflufenacil apresenta propriedades físico-químicas que permitem a sua mobilidade via floema (Ashigh \& Hall 2010) e, consequentemente, a combinação com glifosato, sem que haja prejuízo significativo em seu efeito.

Este estudo objetivou avaliar a eficiência de controle dos herbicidas glifosato e saflufenacil em plantas de buva, bem como o tipo de interação da combinação de glifosato e saflufenacil no controle de buva resistente a glifosato.

\section{MATERIAL E MÉTODOS}

O estudo foi realizado em área experimental do Departamento de Defesa Fitossanitária da Universidade Federal de Santa Maria (RS), no ano agrícola de 2011/2012. A população de plantas foi oriunda da estação experimental da Unicruz, em Cruz Alta (RS), em área com histórico de ocorrência de biótipos de Conyza bonariensis resistentes ao herbicida glifosato.
O experimento foi conduzido em casa-de-vegetação, em delineamento de blocos ao acaso, com quatro repetições, sendo os tratamentos organizados em seis curvas de dose-resposta, cada uma delas com oito doses dos herbicidas glifosato, saflufenacil e combinações de ambos. Os tratamentos (Tabela 1) foram organizados em esquema bifatorial, onde os fatores A e B correspondem aos herbicidas glifosato e saflufenacil, respectivamente.

Foram avaliados o controle da buva, em percentagem, aos 7, 10, 14 e 21 dias após a aplicação (DAT), seguindo-se a escala de 0 a 100 descrita por Frans \& Crowley (1986), e a massa de matéria seca da parte aérea (MMSPA), avaliada aos 21 DAT.

Os tratamentos foram aplicados 45 dias após o transplante das mudas para os vasos, quando as plantas de buva encontravam-se em estágio de roseta, com média de 38 folhas e $1,77 \mathrm{~cm}$ de estatura. A aplicação dos tratamentos foi realizada com pulverizador costal pressurizado com gás carbônico, utilizando-se pontas do tipo leque XR 11002, com pressão de $200 \mathrm{kPa}$ e volume de calda equivalente a $100 \mathrm{~L} \mathrm{ha}^{-1}$. As condições meteorológicas eram adequadas no momento da aplicação dos tratamentos (T: $24,6{ }^{\circ} \mathrm{C}$; UR: 78 \%).

Tabela 1. Tratamentos aplicados sobre plantas de buva (Conyza bonariensis), arranjados em seis curvas de doseresposta, com os herbicidas glifosato, saflufenacil e combinações de ambos (Santa Maria, RS, ano agrícola de 2011/2012).

\begin{tabular}{|c|c|c|c|}
\hline & \multicolumn{3}{|c|}{ Curva de dose-resposta (CDR) } \\
\hline & CDR1 & CDR2 & CDR3 \\
\hline & \multicolumn{3}{|c|}{ Saflufenacil $\left(\mathrm{g} \mathrm{ha}^{-1}\right)$} \\
\hline & 0,00 & 0,55 & 1,09 \\
\hline \multirow{11}{*}{ Glifosato $\left(\mathrm{g} \mathrm{ha}^{-1}\right)^{\mathrm{I}}$} & 0 & 0 & 0 \\
\hline & 270 & 270 & 270 \\
\hline & 540 & 540 & 540 \\
\hline & 1.080 & 1.080 & 1.080 \\
\hline & 2.160 & 2.160 & 2.160 \\
\hline & 4.320 & 4.320 & 4.320 \\
\hline & 8.640 & 8.640 & 8.640 \\
\hline & 17.280 & 17.280 & 17.280 \\
\hline & CDR4 & CDR5 & CDR6 \\
\hline & \multicolumn{3}{|c|}{ Glifosato $\left(\mathrm{g} \mathrm{ha}^{-1}\right)$} \\
\hline & 0 & 270 & 540 \\
\hline \multirow{8}{*}{ Saflufenacil $\left(\mathrm{g} \mathrm{ha}^{-1}\right)$} & 0,00 & 0,00 & 0,00 \\
\hline & 0,55 & 0,55 & 0,55 \\
\hline & 1,09 & 1,09 & 1,09 \\
\hline & 2,18 & 2,18 & 2,18 \\
\hline & 4,37 & 4,37 & 4,37 \\
\hline & 8,75 & 8,75 & 8,75 \\
\hline & 17,50 & 17,50 & 17,50 \\
\hline & 35,00 & 35,00 & 35,00 \\
\hline
\end{tabular}

${ }^{\mathrm{I}}$ Sal de isopropilamina de $\mathrm{N}$-(fosfometil) glicina $\left(360 \mathrm{~g} \mathrm{~L}^{-1}\right)$. 
Os resultados de controle e MMSPA das curvas de dose-resposta foram ajustados pelo modelo de regressão não linear log-logística (Seefeldt et al. 1995), utilizando-se o aplicativo computacional SAS. As regressões de avaliação visual de controle para os herbicidas glifosato e saflufenacil foram ajustadas pelos modelos não lineares logístico e sigmoidal, respectivamente. Para avaliar o tipo de interação da mistura de glifosato e saflufenacil (sinergismo, aditividade ou antagonismo), empregou-se o método

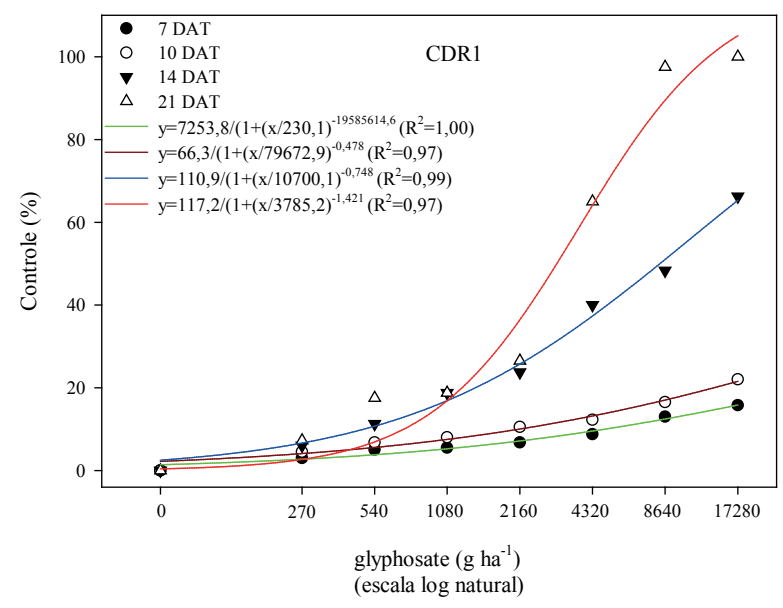

Figura 1. Avaliação visual de controle de buva (Conyza bonariensis), em resposta à aplicação de diferentes doses de glifosato, aos 7, 10, 14 e 21 dias após a aplicação dos tratamentos (DAT) (Santa Maria, RS, ano agrícola de 2011/2012).

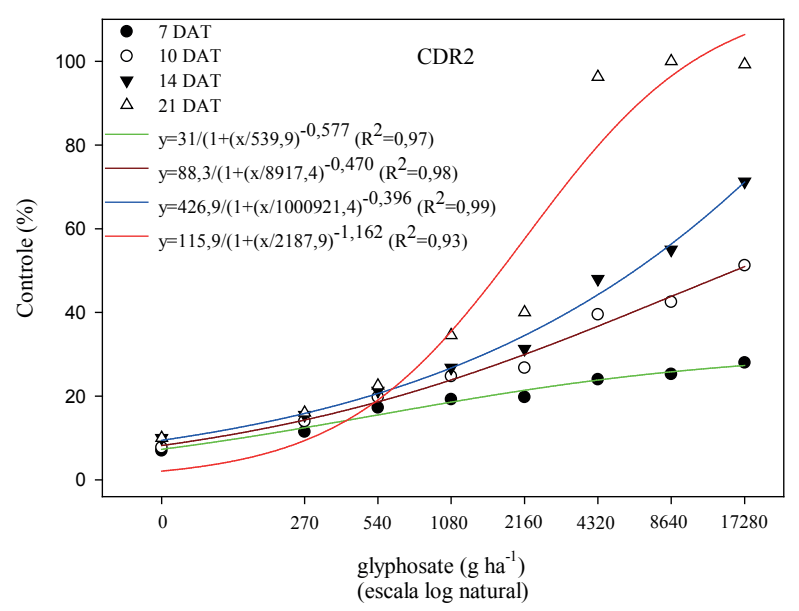

Figura 2. Avaliação visual de controle de buva (Conyza bonariensis), em resposta à aplicação de diferentes doses de glifosato $+0,55 \mathrm{~g} \mathrm{ha}^{-1}$ de saflufenacil, aos 7, 10, 14 e 21 dias após a aplicação dos tratamentos (DAT) (Santa Maria, RS, ano agrícola de 2011/2012). de Colby (1967). A significância estatística foi obtida pela comparação de dois tratamentos de amostras independentes, pelo teste t, a $5 \%$.

\section{RESULTADOS E DISCUSSÃO}

Em relação aos dados de avaliação visual de controle, aos 7 DAT, os sintomas de fitointoxicação foram pouco visíveis nas plantas em que as curvas de dose-resposta tiveram glifosato como o principal herbicida (CDR1, CDR2 e CDR3), apresentando cerca de $15 \%$ de controle (Figuras 1, 2 e 3 ). Por outro lado, nessa mesma avaliação, nas plantas de buva que receberam os tratamentos em que saflufenacil foi o principal herbicida (CDR4, CDR5 e CDR6), os sintomas de fitointoxicação foram marcantes, sobretudo nas doses de $35 \mathrm{~g} \mathrm{ha}^{-1}$ de saflufenacil, apresentando até $80 \%$ de controle (Figuras 4, 5 e 6 ).

Aos 10 e aos 14 DAT, o comportamento foi semelhante ao observado na primeira avaliação, porém, houve incremento no controle em todas as combinações, possivelmente devido ao efeito do glifosato, sobretudo nas maiores doses. Da mesma forma, a adição de saflufenacil contribuiu significativamente para o controle de plantas de buva, sendo que a maior dose da combinação $\left(1,09 \mathrm{~g} \mathrm{ha}^{-1}\right.$ de saflufenacil) apresentou maior injúria, em comparação à menor dose $\left(0,55 \mathrm{~g} \mathrm{ha}^{-1}\right)$ (Figuras 2 e 3$)$.

Aos 21 DAT, observou-se que as maiores doses de glifosato proporcionaram controle superior a

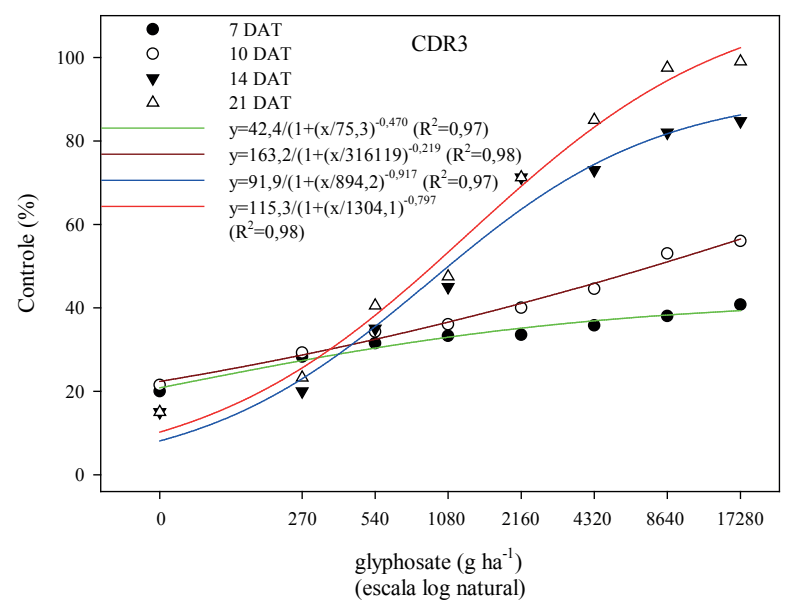

Figura 3. Avaliação visual de controle de buva (Conyza bonariensis), em resposta à aplicação de diferentes doses de glifosato $+1,09 \mathrm{~g} \mathrm{ha}^{-1}$ de saflufenacil, aos 7, 10, 14 e 21 dias após a aplicação dos tratamentos (DAT) (Santa Maria, RS, ano agrícola de 2011/2012). 
$90 \%$, na maioria dos tratamentos. Entretanto, cabe ressaltar que essas doses não apresentam significado agronômico, já que são superiores a $4.320 \mathrm{~g} \mathrm{ha}^{-1} \mathrm{de}$ glifosato, o que corresponde a $24 \mathrm{~L} \mathrm{ha}^{-1}$ de produto comercial. Assim como nas demais avaliações, aos 21 DAT, a adição de saflufenacil ao glifosato (CDR2 e CDR3), em ambas as doses utilizadas $\left(0,55 \mathrm{~g} \mathrm{ha}^{-1}\right.$ e 1,09 $\mathrm{g} \mathrm{ha}^{-1}$ ), proporcionou melhor controle, em relação à curva de dose-resposta composta apenas por glifosato (CDR1) (Figuras 1, 2 e 3).

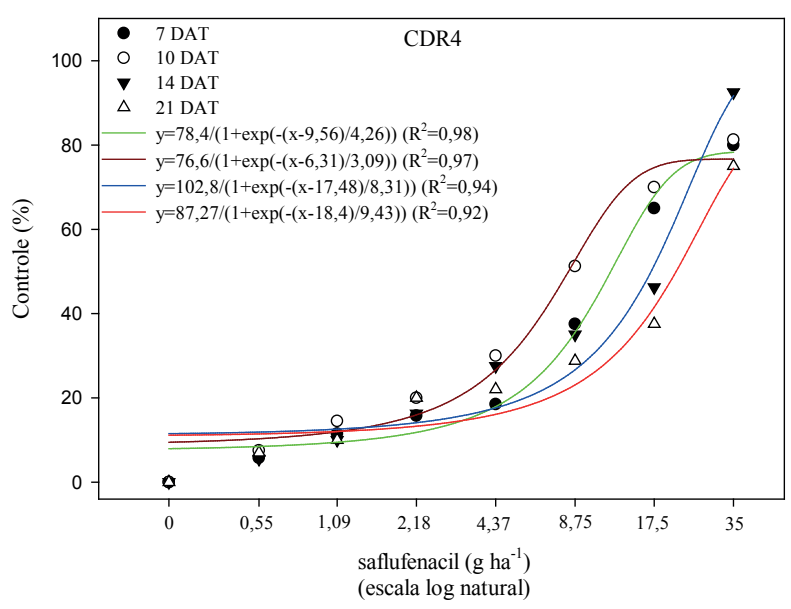

Figura 4. Avaliação visual de controle de buva (Conyza bonariensis), em resposta à aplicação de diferentes doses de saflufenacil, aos 7, 10, 14 e 21 dias após a aplicação dos tratamentos (DAT) (Santa Maria, RS, ano agrícola de 2011/2012).

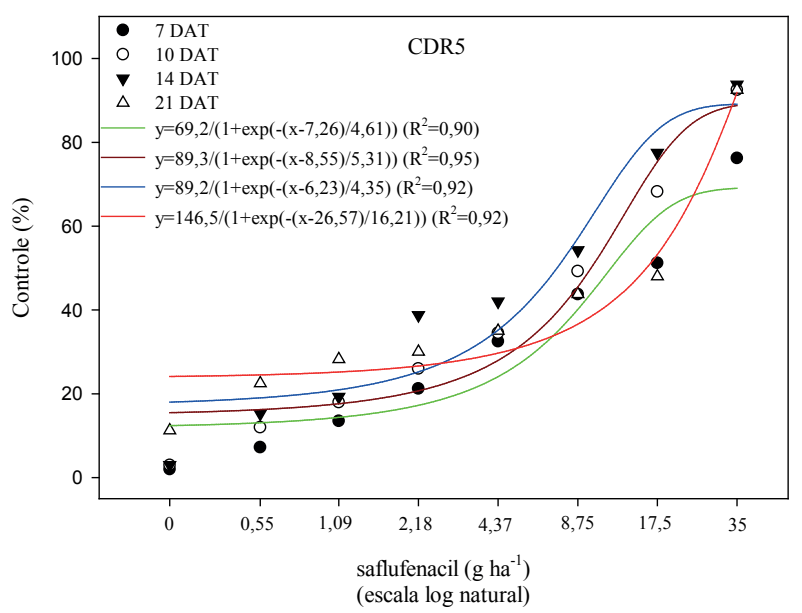

Figura 5. Avaliação visual de controle de buva (Conyza bonariensis), em resposta à aplicação de diferentes doses de saflufenacil $+270 \mathrm{~g} \mathrm{ha}^{-1}$ de glifosato, aos 7, 10, 14 e 21 dias após a aplicação dos tratamentos (DAT) (Santa Maria, RS, ano agrícola de 2011/2012).
A adição de saflufenacil ao glifosato no controle de espécies de buva tem se mostrado eficiente em alguns estudos. No caso de $C$. canadensis, a mistura de $900 \mathrm{~g} \mathrm{ha}^{-1}$ de glifosato com $25 \mathrm{~g} \mathrm{ha}^{-1}$ de saflufenacil proporcionou controle superior a $95 \%$ das plantas (Byker et al. 2013). Em outro trabalho, a adição de glifosato permitiu a redução da dose de saflufenacil, sem que o controle de C. canadensis fosse prejudicado. A aplicação de $25 \mathrm{~g} \mathrm{ha}^{-1}$ de saflufenacil, juntamente com glifosato $\left(840 \mathrm{~g} \mathrm{ha}^{-1}\right)$, proporcionou controle semelhante à aplicação de $50 \mathrm{~g} \mathrm{ha}^{-1}$ de saflufenacil isoladamente (Mellendorf et al. 2013).

Além do controle da buva, é importante ressaltar a importância da combinação de glifosato ao saflufenacil na manutenção desse controle. Embora as doses de glifosato $\left(270 \mathrm{~g} \mathrm{ha}^{-1} \mathrm{e} 540 \mathrm{~g} \mathrm{ha}^{-1}\right)$ combinadas ao saflufenacil nesses experimentos sejam inferiores àquelas utilizadas no campo (1.080-2.160 $\left.\mathrm{g} \mathrm{ha}^{-1}\right)$, elas foram suficientes para prevenir a ocorrência de rebrote das plantas de buva (Figuras 5 e 6 ).

Portanto, as doses de saflufenacil que estão dentro do intervalo recomendado para o controle de buva (24,5-35 $\left.\mathrm{g} \mathrm{ha}^{-1}\right)$ promoveram o controle das plantas até o período de duas semanas após a aplicação do herbicida, com ocorrência de rebrote a partir da terceira semana (Figura 4). Entretanto, com a associação de glifosato a essas doses de saflufenacil, não houve a ocorrência de rebrote (Figuras 5 e 6). Resultados semelhantes foram obtidos por Morichetti et al. (2012), que, ao estudarem

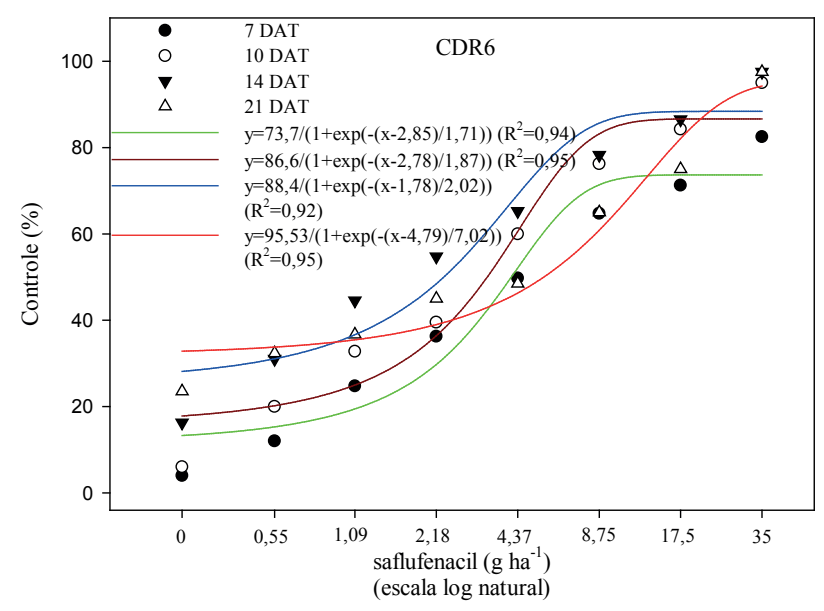

Figura 6. Avaliação visual de controle de buva (Conyza bonariensis), em resposta à aplicação de diferentes doses de saflufenacil $+540 \mathrm{~g} \mathrm{ha}^{-1}$ de glifosato, aos 7, 10, 14 e 21 dias após a aplicação dos tratamentos (DAT) (Santa Maria, RS, ano agrícola de 2011/2012). 
a eficiência de controle de saflufenacil aplicado em pós-emergência sobre Commelina benghalensis e Amaranthus palmeri, constataram que o controle foi melhor aos 7 DAT, com redução na eficiência aos 14 e 28 DAT, devido à recuperação das plantas. Da mesma forma, na figura 4 (doses de saflufenacil sem a adição de glifosato), pode-se observar que os melhores níveis de controle ocorrem aos 7 e 10 DAT, com redução do efeito aos 14 e 21 DAT, devido à recuperação das plantas.

$\mathrm{O}$ aumento da dose de glifosato proporcionou redução na produção de massa de matéria seca da parte aérea (MMSPA) da buva avaliada aos 21 DAT (Figura 7). Para a CDR1, a dose de herbicida que proporcionou a redução de $50 \%$ da MMSPA $\left(\mathrm{GR}_{50}\right)$ foi de $1.155,9 \mathrm{~g} \mathrm{ha}^{-1}$ de glifosato. Na CDR2, com a adição de $0,55 \mathrm{~g} \mathrm{ha}^{-1}$ de saflufenacil à curva de dose-resposta composta por glifosato (CDR1), ocorreu redução da MMSPA e, consequentemente, da $\mathrm{GR}_{50}$ de glifosato, em relação à aplicação apenas de glifosato. Ao se adicionar saflufenacil, a GR $\mathrm{G}_{50}$ foi reduzida para $692 \mathrm{~g} \mathrm{ha}^{-1}$ de glifosato. De forma semelhante, na CDR3, ao se adicionar $1,09 \mathrm{~g} \mathrm{ha}^{-1}$ de saflufenacil às diferentes doses de glifosato, também ocorreu redução na $\mathrm{GR}_{50}$, sendo de 788 g ha $^{-1}$ de glifosato. Assim como na $\mathrm{GR}_{50}$, com a adição de saflufenacil ao glifosato, também houve redução na MMSPA das plantas de buva.

A alta $\mathrm{GR}_{50}\left(1.155,9 \mathrm{~g} \mathrm{ha}^{-1}\right.$ de glifosato) indica que a população de buva utilizada neste estudo é resistente a este herbicida. Moreira et al. (2007) encontraram valores de $\mathrm{GR}_{50}$ em torno de $750 \mathrm{~g} \mathrm{ha}^{-1}$ de glifosato, para a mesma variável (MMSPA), em população de $C$. bonariensis considerada resistente.

Para as curvas de dose-resposta em que saflufenacil foi o principal herbicida (CDR4, CDR5 e CDR6) (Figura 8), as respostas foram semelhantes ao comportamento observado ao se utilizar glifosato como herbicida principal. Ou seja, a adição de glifosato às doses de saflufenacil proporcionou redução na produção de MMSPA e também nas $\mathrm{GR}_{50}$.

$\mathrm{Na}$ curva de dose-resposta formada apenas pela variação das doses de saflufenacil (0-35 $\left.\mathrm{g} \mathrm{ha}^{-1}\right)$ (CDR4), a GR ${ }_{50}$ para este herbicida foi de 5,43 $\mathrm{g} \mathrm{ha}^{-1}$. Nas duas demais curvas de dose-resposta em que saflufenacil foi o principal herbicida, ao se misturar $270 \mathrm{~g} \mathrm{ha}^{-1}$ (CDR5) e $540 \mathrm{~g} \mathrm{ha}^{-1}$ de glifosato (CDR6), as $\mathrm{GR}_{50}$ foram reduzidas para $1,18 \mathrm{~g} \mathrm{ha}^{-1} \mathrm{e} 0,70 \mathrm{~g} \mathrm{ha}^{-1}$ de saflufenacil, respectivamente, demonstrando a contribuição do glifosato ao saflufenacil no controle das plantas de buva. O aumento da dose de saflufenacil promoveu redução na MMSPA, assim como ocorreu para as curvas de dose-resposta em que se adicionou saflufenacil ao glifosato.

Embora a maioria das doses de saflufenacil utilizadas neste trabalho possa ser considerada baixa, em relação àquelas recomendadas pelo fabricante para C. bonariensis $\left(24,5-35 \mathrm{~g} \mathrm{ha}^{-1}\right)$, a visualização

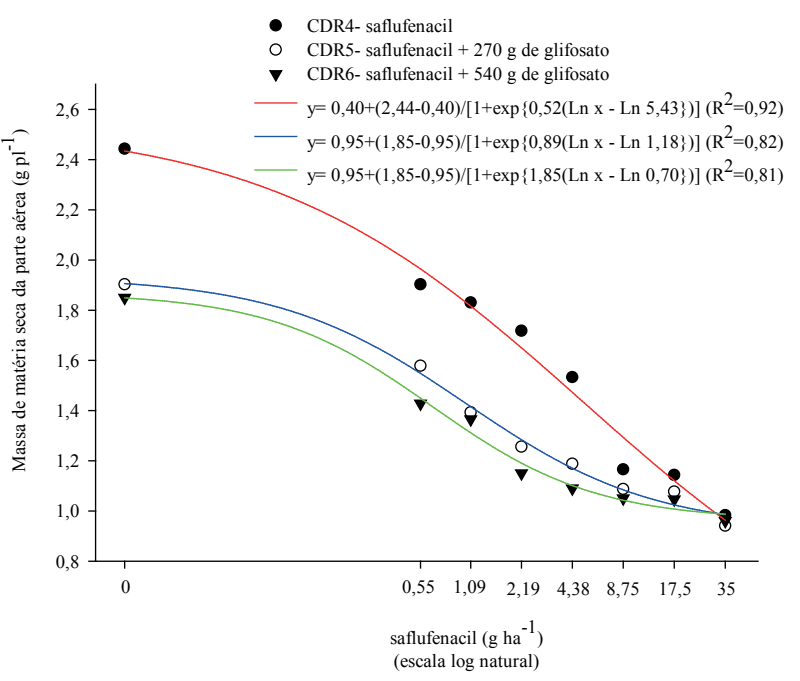

Figura 8. Massa de matéria seca da parte aérea $\left(\mathrm{g} \mathrm{planta}^{-1}\right) \mathrm{de}$ buva (Conyza bonariensis), em resposta a aplicações de saflufenacil e glifosato, aos 21 dias após a aplicação dos tratamentos (21 DAT) (Santa Maria, RS, ano agrícola de 2011/2012). 
do efeito da mistura desse herbicida com glifosato poderia ser prejudicada, caso as doses fossem maiores.

Os resultados obtidos podem ser associados a trabalhos realizados com outra espécie de buva (Conyza canadensis) e também com outras plantas daninhas. Geier et al. (2009), estudando a eficiência de saflufenacil sobre Chorispora tenella, Descurainia sophia, Amaranthus palmeri, Amaranthus retroflexus e Amaranthus albus, verificaram que a aplicação de $9 \mathrm{~g} \mathrm{ha}^{-1}$ proporcionou redução de biomassa superior a $90 \%$, para todas as espécies estudadas.

Os resultados referentes à análise do efeito da interação dos herbicidas pelo método de Colby (1967) sobre a variável produção de MMSPA demonstram que todos os valores esperados para a mistura foram superiores aos valores observados $(\mathrm{t}<0,05)$, independentemente das doses (Tabela 2). Para a avaliação visual de controle aos 21 DAT, o comportamento foi semelhante ao observado para a MMSPA, ou seja, os efeitos foram mais satisfatórios do que os valores esperados pelo método de Colby (1967). Desse modo, os resultados obtidos demonstram a ocorrência de sinergismo entre os herbicidas glifosato e saflufenacil, no controle de buva.

O sinergismo observado neste trabalho concorda com os resultados observados por Waggonner et al. (2011), em outra espécie de buva (C. canadensis), em que saflufenacil $\left(25 \mathrm{~g} \mathrm{ha}^{-1}\right)$ e glifosato (1.061 $\left.\mathrm{g} \mathrm{ha}^{-1}\right)$ obtiveram controles de $65 \%$ e $46 \%$, respectivamente, aos 30 DAT, enquanto que, ao serem aplicados em mistura, o controle observado foi de $96 \%$. Aplicando-se o método de Colby (1967) para esses resultados, o controle esperado seria de $81 \%$, indicando o efeito sinérgico da mistura.

Cabe ressaltar que é recomendada a aplicação de saflufenacil juntamente com adjuvante específico (Grossmann et al. 2011). Em trabalho realizado por Ashigh \& Hall (2010), constatou-se ocorrer maior absorção de saflufenacil, quando misturado com adjuvante e/ou glifosato sobre plantas de repolho. No entanto, observou-se reduzida translocação de glifosato. Segundo os autores, na presença de adjuvante, o herbicida saflufenacil apresenta rápida

Tabela 2. Massa de matéria seca da parte aérea (MMSPA) relativa e controle de buva observados e interação esperada pelo método de Colby (1967), em resposta à combinação de glifosato com saflufenacil (Santa Maria, RS, ano agrícola de 2011/2012).

\begin{tabular}{|c|c|c|c|c|c|c|}
\hline Tratamentos & \multicolumn{3}{|c|}{ MMSPA relativa (\%) } & \multicolumn{3}{|c|}{ Controle (\%) aos 21 DAT } \\
\hline $\begin{array}{l}\text { Glifosato + saflufenacil } \\
\left(\mathrm{g} \text { e.a. } \mathrm{ha}^{-1}+\mathrm{g} \text { i.a. } \mathrm{ha}^{-1}\right)\end{array}$ & Esperado & Observado & Prob $t^{I}$ & Esperado & Observado & Prob t \\
\hline $270+0,55$ & 93,44 & 61,72 & $<0,001$ & 13,74 & 16,00 & $<0,001$ \\
\hline $540+0,55$ & 93,30 & 58,34 & $<0,001$ & 23,28 & 22,50 & $0,260^{\mathrm{ns}}$ \\
\hline $1080+0,55$ & 90,47 & 57,73 & $<0,001$ & 24,44 & 34,50 & $<0,001$ \\
\hline $2160+0,55$ & 89,02 & 45,14 & $<0,001$ & 31,65 & 40,00 & 0,002 \\
\hline $4320+0,55$ & 86,48 & 40,94 & $<0,001$ & 67,45 & 96,25 & $<0,001$ \\
\hline $270+1,09$ & 94,05 & 59,57 & $<0,001$ & 16,53 & 23,25 & $<0,001$ \\
\hline $540+1,09$ & 93,92 & 55,89 & $<0,001$ & 25,75 & 40,50 & $<0,001$ \\
\hline $1080+1,09$ & 91,35 & 52,20 & $<0,001$ & 26,88 & 47,50 & $<0,001$ \\
\hline $2160+1,09$ & 90,04 & 47,90 & $<0,001$ & 33,85 & 71,25 & $<0,001$ \\
\hline $4320+1,09$ & 87,73 & 39,61 & $<0,001$ & 68,50 & 85,00 & $<0,001$ \\
\hline Tratamentos & \multicolumn{3}{|c|}{ MMSPA relativa (\%) } & \multicolumn{3}{|c|}{ Controle aos 21 DAT $(\%)$} \\
\hline $\begin{array}{l}\text { Saflufenacil + glifosato } \\
\left(\text { g i.a. }^{-1}+\mathrm{g}^{-1} \text { e.a. } \mathrm{ha}^{-1}\right)\end{array}$ & Esperado & Observado & Prob t & Esperado & Observado & Prob t \\
\hline $2,18+270$ & 92,95 & 51,38 & $<0,001$ & 25,80 & 30,00 & 0,006 \\
\hline $4,37+270$ & 91,15 & 50,56 & $<0,001$ & 27,66 & 35,00 & 0,003 \\
\hline $8,75+270$ & 87,58 & 50,67 & $<0,001$ & 33,92 & 43,75 & 0,002 \\
\hline $17,50+270$ & 87,36 & 47,59 & $<0,001$ & 42,03 & 48,00 & 0,035 \\
\hline $35,00+270$ & 85,81 & 44,01 & $<0,001$ & 76,81 & 92,50 & $<0,001$ \\
\hline $2,18+540$ & 92,80 & 48,11 & $<0,001$ & 34,00 & 45,00 & $<0,001$ \\
\hline $4,37+540$ & 90,96 & 44,63 & $<0,001$ & 35,65 & 48,50 & $<0,001$ \\
\hline $8,75+540$ & 87,31 & 47,39 & $<0,001$ & 41,22 & 57,50 & $<0,001$ \\
\hline $17,50+540$ & 87,09 & 43,40 & $<0,001$ & 48,44 & 60,00 & 0,005 \\
\hline $35,00+540$ & 85,50 & 39,30 & $<0,001$ & 79,38 & 97,50 & $<0,001$ \\
\hline
\end{tabular}

${ }^{\mathrm{I}}$ Teste t, com significância na probabilidade indicada; ${ }^{\text {ns }}$ não significativo. 
ação de contato, causando morte de células, o que resulta em menor translocação do glifosato. Da mesma forma, o herbicida saflufenacil, assim como o óleo vegetal concentrado utilizado como adjuvante, causaram aumento da absorção (6\%) e redução na translocação (6\%) do herbicida glifosato, em plantas de C. canadensis. Embora tenha causado redução na translocação, a presença de saflufenacil proporcionou aumento equivalente na absorção do glifosato, o que pode contribuir para a ocorrência de sinergismo (Eubank et al. 2013).

$O$ tipo de interação resultante das misturas de glifosato com inibidores de PPO tem sido mais frequentemente de antagonismo. Herbicidas que apresentam como sintoma a rápida necrose podem causar a disrupção da membrana celular, inibindo a absorção e translocação de outros herbicidas, quando aplicados em mistura (Eubank et al. 2013). No caso do saflufenacil, no entanto, mesmo pertencendo a esse mecanismo de ação, suas características físico-químicas peculiares $\left(\mathrm{pK}_{\mathrm{a}}\right.$ de 4,41 e $\log \mathrm{K}_{\text {ow }}$ de 2,6) lhe conferem caráter sistêmico, o que pode explicar o sinergismo observado.

A sua distribuição sistêmica pode ser explicada pelo seu fraco caráter ácido e, também, pela estabilidade metabólica em plantas daninhas dicotiledôneas (Grossmann et al. 2011). Essas características o colocam na região limítrofe da mobilidade no floema/ xilema e mobilidade apenas no xilema (Bromilow et al. 1990).

Embora a quantidade translocada seja similar à de outros herbicidas inibidores de PPO, a aplicação de saflufenacil em apenas uma folha de maria-pretinha (Solanum americanum) causou a morte da planta, demonstrando a sua translocação, o que não ocorreu com a aplicação de flumioxazin e butafenacil (Grossmann et al. 2011). Dessa forma, além de aumentar a quantidade de glifosato absorvida, sem exercer a ação tópica imediata de seus pares inibidores de PPO, o saflufenacil deve permitir a mobilidade de grande parte do glifosato absorvido, resultando, assim, na possível interação sinérgica observada, ao contrário do que ocorre com outros herbicidas inibidores da enzima PPO, quando aplicados juntamente com glifosato.

\section{CONCLUSÕES}

1. Existe relação sinérgica entre os herbicidas glifosato e saflufenacil no controle de plantas de buva.
2. A aplicação isolada de saflufenacil não é a melhor estratégia de controle de buva, uma vez que as plantas apresentam rebrote a partir da segunda semana após o tratamento. Portanto, a adição de glifosato (540 $\mathrm{g} \mathrm{ha}^{-1}$ ) ao herbicida saflufenacil (35 $\mathrm{g} \mathrm{ha}^{-1}$ ), além de melhorar o controle da buva, também previne o rebrote das plantas.

\section{REFERÊNCIAS}

ASHIGH, J. J.; HALL, C. Bases for interactions between saflufenacil and glyphosate in plants. Journal of Agricultural and Food Chemistry, Davis, v. 58, n. 12, p. 7335-7343, 2010.

BEALE, S. I.; WEINSTEIN, J. D. Tetrapyrrole metabolism in photosynthetic organisms. In: DAILEY, H. A. (Ed.). Biosynthesis of heme and chlorophyll. New York: McGraw-Hill, 1990. p. 287-391.

BROMILOW, R. H. K. et al. Physico-chemical aspects of phloem translocation of herbicides. Weed Science, Champaign, v. 38, n. 3, p. 305-314, 1990.

BYKER, H. P. et al. Control of glyphosate-resistant Canada fleabane [Conyza canadensis (L.) Cronq.] with preplant herbicide tankmixes in soybean [Glycine max (L). Merr.]. Canadian Journal of Plant Science, Ottawa, v. 93, n. 4, p. 659-667, 2013.

COLBY, S. R. Calculating synergistic and antagonistic responses of herbicide combinations. Weeds, Urbana, v. 15, n. 1, p. 20-22, 1967.

CULPEPPER, A. S. Glyphosate-induced weed shifts. Weed Technology, Champaign, v. 20, n. 2, p. 277-281, 2006.

EUBANK, T. W. et al. Saflufenacil efficacy on horseweed and its interaction with glyphosate. Weed Biology and Management, Malden, v. 13, n. 4, p. 135-143, 2013.

FRANS, R.; CROWLEY, H. Experimental design and techniques for measuring and analyzing plant responses to weed control practices. In: CAMPER, D. (Ed.). Research methods in weed science. 3. ed. Champaign: Southern Weed Science Society, 1986. p. 29-45.

GEIER, P. W. et al. Dose responses of five broadleaf weeds to saflufenacil. Weed Technology, Champaign, v. 23, n. 2, p. 313-316, 2009.

GROSSMANN, K. et al. Saflufenacil (Kixor ${ }^{\mathrm{TM}}$ ): biokinetic properties and mechanism of selectivity of a new protoporphyrinogen IX oxidase inhibiting herbicide. Weed Science, Champaign, v. 59, n. 3, p. 290-298, 2011.

GROSSMANN, K. et al. The herbicide saflufenacil $\left(\right.$ Kixor $^{\mathrm{TM}}$ ) is a new inhibitor of protoporphyrinogen IX oxidase activity. Weed Science, Champaign, v. 58, n. 1, p. 1-9, 2010. 
HEAP, I. Global perspective of herbicide-resistant weeds. Pest Management Science, Oxford, v. 70, n. 9, p. 13061315, 2014.

LAMEGO, F. P.; VIDAL, R. A. Resistência ao glyphosate em biótipos de Conyza bonariensis e Conyza canadensis no Estado do Rio Grande do Sul, Brasil. Planta Daninha, Viçosa, v. 26, n. 2, p. 467-471, 2008.

MELLENDORF, T. G. et al. Influence of plant height and glyphosate on saflufenacil efficacy on glyphosate-resistant horseweed (Conyza canadensis). Weed Technology, Champaign, v. 27, n. 3, p. 463-467, 2013.

MOREIRA, M. S. et al. Resistência de Conyza canadensis e Conyza bonariensis ao herbicida glyphosate. Planta Daninha, Viçosa, v. 25, n. 1, p. 157-164, 2007.

MORICHETTI, S. et al. Weed management and peanut response from applications of saflufenacil. Weed Technology, Champaign, v. 26, n. 2, p. 261-266, 2012.

RODRIGUES, B. N.; ALMEIDA, F. S. Guia de herbicidas. 5. ed. Londrina: Ed. dos Autores, 2011.

SEEFELDT, S. S. et al. Log-logistic analysis of herbicide dose-response relationships. Weed Technology, Champaign, v. 9, n. 1, p. 218-225, 1995.
SHAW, D. R.; ARNOLD, J. C. Weed control from herbicide combinations with glyphosate. Weed Technology, Champaign, v. 16, n. 1, p. 1-6, 2002.

STARKE, R. J.; OLIVER, L. R. Interaction of glyphosate with chlorimuron, fomesafen, imazetaphyr, and sulfentrazone. Weed Science, Champaign, v. 46, n. 6, p. 652-660, 1998

WAGGONER, B. S. et al. Control of glyphosate-resistant horseweed (Conyza canadensis) with saflufenacil tank mixtures in no-till cotton. Weed Technology, Champaign, v. 25 , n. 3, p. 310-315, 2011.

WILSON, R. G. et al. Glyphosate-induced weed shifts in glyphosate-resistant corn or a rotation of glyphosate-resistant corn, sugarbeet, and spring wheat. Weed Technology, Champaign, v. 21, n. 4, p. 900-909, 2007.

ZABLOTOWICZ, R. M.; REDDY, K. N. Nitrogenase activity, nitrogen content, and yield responses to glyphosate in glyphosate-resistant soybean. Crop Protection, Guildford, v. 26, n. 3, p. 370-376, 2007. 